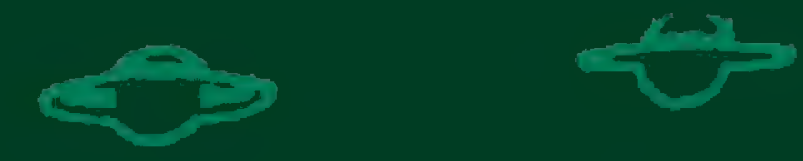

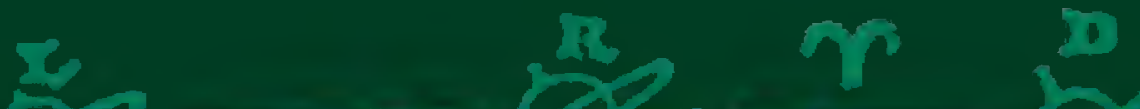

$\mathbb{N}$ ALBERT VAN HELDEN

\section{HUYGENS'S RING}

CASSINI'S DIVISION \&

\section{SATURN'S CHILDREN}

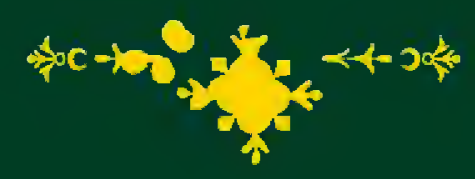

DIBNER LIBRARY LECTURE

$$
27 \text { OCTOBER, } 2004
$$

SMITHSONIAN INSTITUTION LIBRARIES 



\section{HUYGENS’S RING, \\ CASSINI'S DIVISION \&}

SATURN'S CHILDREN

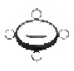

I N COMMEMORATION OF THE F O URTEEN TH A N N UA L

D I B N ER L I B R A R Y L E C T U R E S E R I E S 



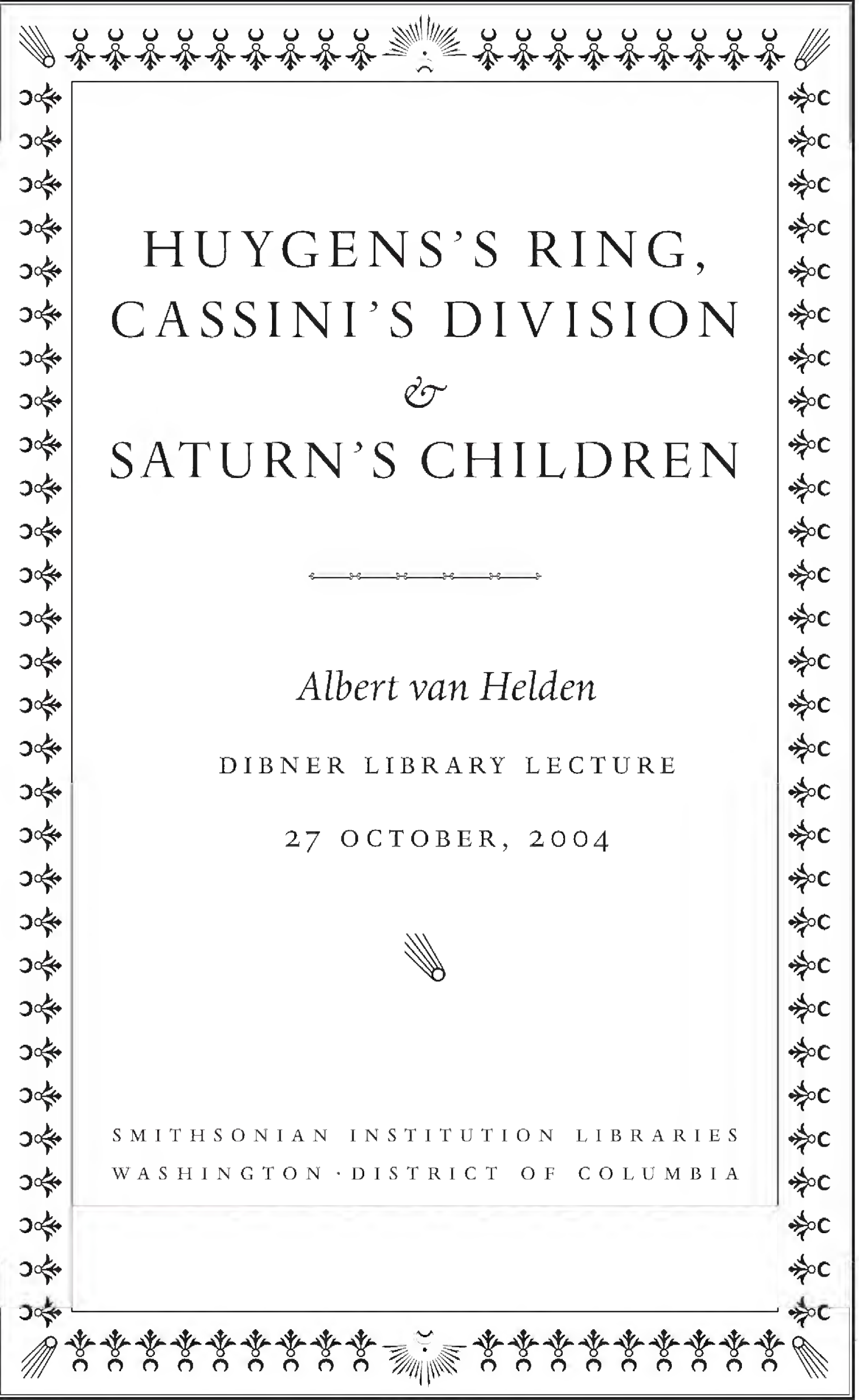


PUBLISHED BY SMITHSONIAN 1NSTITUTION LIBRARIES

WASHINGTON, DC 200I3-7OI2

Text Copyright C 2006 Albert van Helden. All rights reserved.

Albert van Helden is Professor Emeritus at Rice University and the University of Utrecht, Netherlands, where he resides and teaches on a regular basis. He received his B.S and M.S. from Stevens Institute of Technology, M.A. from the University of Michigan and Ph.D. from Imperial College, University of London. Van Helden is a renowned author who has published respected books and articles about the history of science, including the translation of Galileo's "Sidereus Nuncius" into English. He has numerous periodical contributions to his credit and has served on the editorial boards of Air and Space, 1990-present; Journal for the History of Astronomy, I988-present; Isis, I989-I994; and Tractrix, I989-1995.

During his tenure at Rice University (1970-2001), van Helden was instrumental in establishing the "Galileo Project,"a Web-based source of information on the life and work of Galileo Galilei and the science of his time. A native of the Netherlands, Professor van Helden returned to his homeland in $200 \mathrm{r}$ to join the faculty of Utrecht University.

Edited by Robert Kearns

Designed and typeset by Marc Alain Meadows

Meadows Design Office, Inc., Washington, DC, www.mdomedia.com

LIBRARY OF CONGRESS CATALOGING-IN-PUBLICATION DATA

Van Helden. Albert.

Huygens's ring, Cassini's division, and Saturn's children / by Albert van Helden. p. cm. - (Dibner Library lecture ; 27 October 2004)

Includes bibliographical references.

I. Telescopes. 2. Discoveries in science. I. Title. 
HUYGENS'S RING, CASSINI'S DIVISION AND SATURN'S CHILDREN 


\section{F O R E W O R D}

ysterious Saturn is the subject of this intriguing essay by Al-
bert van Helden, Professor Emeritus at Rice University and
the University of Utrecht. Calling Saturn "with its system of rings and satellites... the most splendid object in the solar system revealed by the telescope," van Helden shows what an important object of research the planet has been for four centuries, made popular again with NASA's 2004 Cassini-Huygens Mission, which placed a probe on Titan, one of Saturn's satellites. Thus, the subject of the I4TH annual Dibner Library Lecture is at once historical and contemporary and shows once again the value of the collections housed in the Dibner Library of the History of Science and Technology.

Bern Dibner (1897-1988) is the individual responsible for bringing together the remarkable collection of books now housed in the library that bears his name, one of two rare book facilities among the twenty branches of the Smithsonian Institution Libraries. An electrical engineer, book collector, and philanthropist, Dr. Dibner donated over 8,000 volumes of rare scientific and technological works from his Burndy Library to the Smithsonian on the occasion of the United States Bicentennial celebration in 1976 . He considered it a gift to the nation responsible for his success. 'This splendid donation is the core of the Libraries' exceptional physical sciences collection and contains many major works dating from the fifteenth to the early nineteenth centuries in engineering, transportation, chemistry, mathematics, physics, electricity, and, as this essay demonstrates, astronomy.

We thank The Dibner Fund for supporting the lecture series and its publications. Staff of the Libraries' Special Collections Department and Public Affairs Office helped with various aspects of planning for the lec- 
ture and production of this booklet. We are also grateful to Albert van Helden, who produced both an entertaining lecture and excellent manuscript for future readers. We hope you enjoy it.

For more information, please see the home page of the Dibner Library of the History of Science and Technology at www.sil.si.edu/Libra ries/Dibner/. To see Dr. van Helden's lecture and a list of all the other Dibner Library Lectures, go to www.sil.si.edu/ exhibitions/lectures.htm.

Nancy E. Gwinn

Director, Smithsonian Institution Libraries

August 2006 


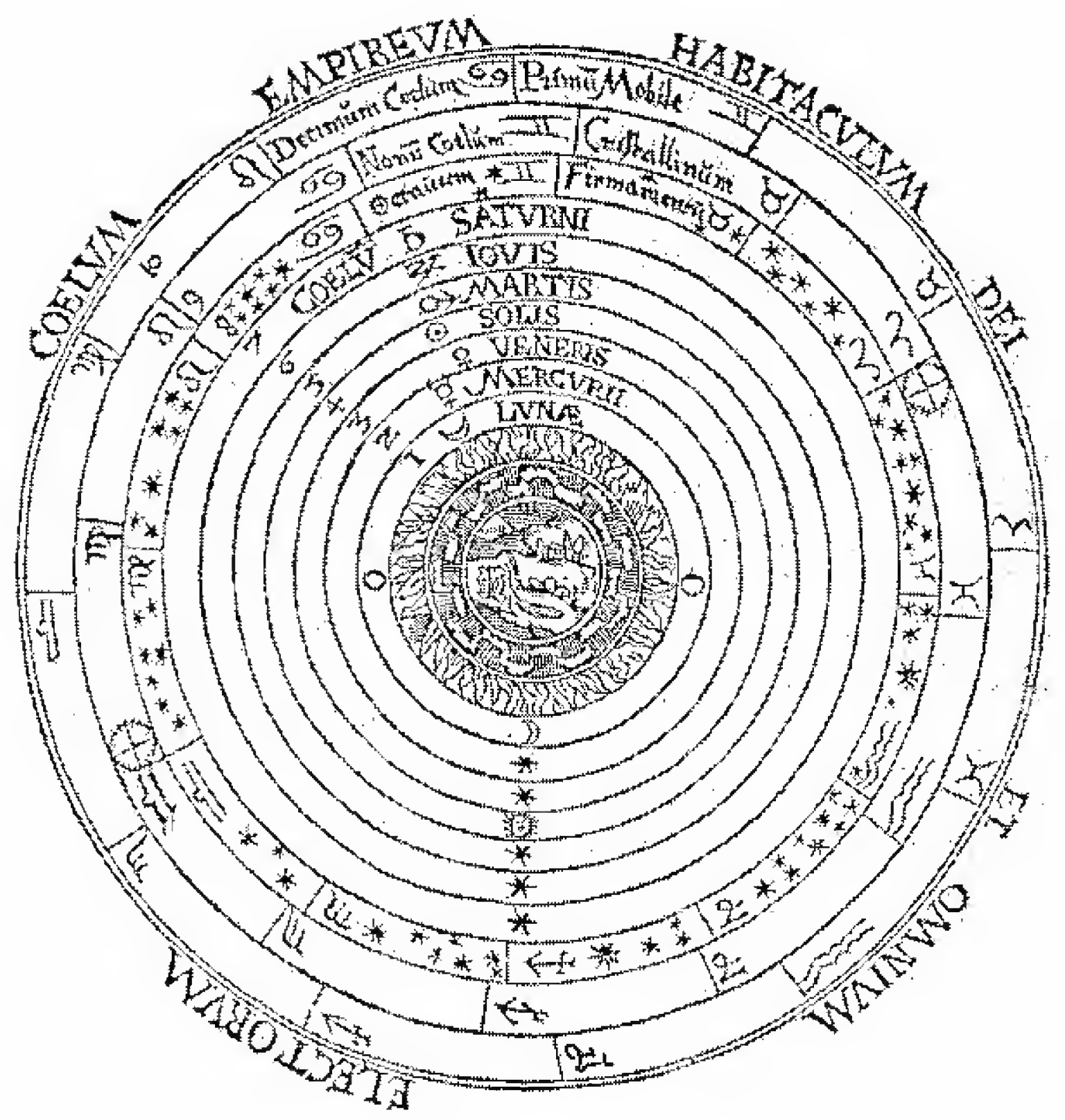




\section{HUYGENS'S RING, \\ CASSINI’S DIVISION \\ \& \\ SATURN'S CHILDREN}

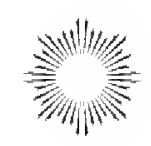

he planet Saturn with its system of rings and satellites is the
most splendid object in the solar system revealed by the tele-
scope. The ring system has also been an important research subject for four centuries. The recent Cassini mission to explore the planet and its surrounding rings, with its embedded Huygens probe making a spectacular landing on the intriguing moon Titan, has put the planet once again in the popular and scientific news. I say "once again," because in the seventeenth century the planet was also frequently in the news. Its appearance was a scientific problem, and the discoveries made about it were celebrated at courts as well as scientific meetings. This paper is about those early years of telescopic discovery.

Between 1609 and the end of the seventeenth century, astronomy and cosmology were profoundly changed by a new instrument, the telescope. No one could have suspected that in the middle of a cosmological debate in learned circles-about whether the Earth or the Sun was the center of the universe - a flood of astounding new information would come from an entirely new direction and would transform the cosmological debate from a rather esoteric argument carried on by schol- 
ars in Latin to a public issue on the tongues of the entire literate population of Europe (and beyond). The telescope did not prove that the Sun was the center and the Earth in the "third heaven," but the information it injected into the deliberations made a lot more sense in the context of a sun-centered theory. The telescope, therefore, not only changed the terms of the debate, it answered some pressing questions about the heliocentric option.

The cosmos of Aristotle (figure I), which ruled unopposed right up to the time of Copernicus was a thing of beauty. The Earth, stage for the human drama, was in the center, there was a place for everything - it was, in fact, a universe of places, not of spaces - and there was an absolute divide between the heavens and the earthly regions. The heavens

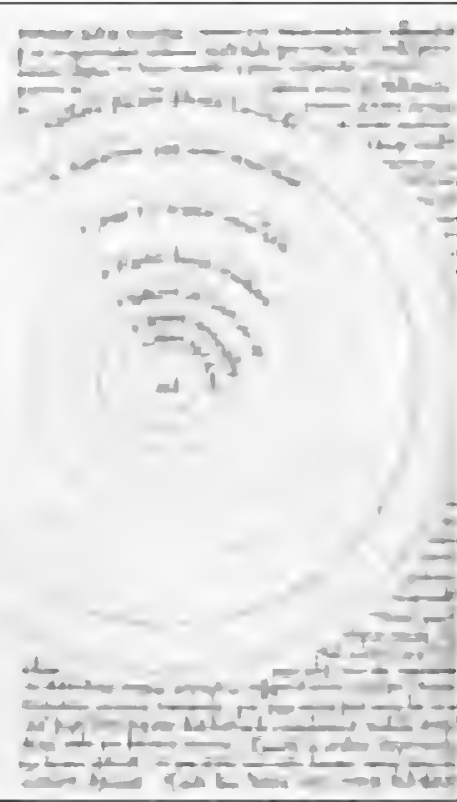

FIGURE 2. The cosmos acording to Copernicus. De Revolutionibus Orbium Coelestium (Nuremberg, 1543). were perfect and unchanging; the lower realms were changeable and corrupt. For most, the center of the Earth, the most corrupt place in the universe, was the place of hell; the empyrean heaven, the abode of God, was situated at the periphery. It was a beautiful structure that gave a physical explanation but also supported values,

Now, by the simple move of exchanging the places of the Earth and Sun (figure 2), Copernicus undermined everything. The Earth was now a planet in the heavens, the distinction between the corrupt earthly region and the perfect heaven was abolished: Was the Earth now perfect or were the heavens corrupt? If, in the old system a stone fell to the center of the universewhich is also the center of the Earth - because that was its natural place, then how was one to explain that motion when the center of the Earth was no longer the center of the universe and constantly moving from 
place to place? In other words, one was left without physics (that is, a causal account of why objects move as they do).Clearly, this simple change proposed by Copernicus meant that one had to give up an entire system of thought and construct a new one. That process took a century and a half. Indeed, most students of heavenly things ignored Copernicus's cosmological theory and concentrated on the rest of his book, in which he completely recast technical astronomy along heliocentric lines. But since we, as observers, are on the Earth, not on the Sun, we still have to refer our predictions to the Earth; and thus, one could just treat Copernicus's cosmological claim as a convenient mathematical hypothesis. Robert Westman has shown that between 1543 , when Copernicus's book was published, and the turn of the seventeenth century, perhaps only a dozen scholars accepted Copernicus's theory as representing reality.

Some of the questions that were raised by opponents of heliocentrism during this early period were: If the Earth is a planet, then why is it the only planet to have a moon? Why is there more than one center of motion/rotation in the universe? If the Copernican theory predicts that the stars are so far away (they have to be in order to explain the lack of annual stellar parallax), then why do they not appear smaller? In the old cosmology there were seven planets; now, because the Moon is eliminated from the sequence, there are only six-why six? These questions strike us as strange, but they show just how uncomfortable this new cosmology was for people. I do not need to remind you that an Earth spinning on its axis and traveling around the Sun violated their common sense. Finally, there was the question about Scripture, which seemed clearly to indicate that the Earth does not move. But all these questions were matters of philosophy, hardly noticed by a larger public. Those teaching astronomy in the universities, even if they were "Copernicans," continued to teach the older earth-centered books because these were stipulated in their contracts. 
It was into this situation that the telescope was introduced. First made public in the Dutch Republic, low-powered spyglasses quickly spread over Europe. In Padua, Galileo Galilei, professor of Mathematical sciences at the university there, seized on the device and quickly turned it into a highpowered scientific instrument-slightly more powerful than our ordinary binoculars. And with it, he reaped a rich harvest of phenomena that lie just slightly beyond the power of the naked eye. These were as follows:

$\therefore$ The surface of the Moon is not perfectly spherical, as befits a heavenly body, but rather is mountainous.

$\therefore$ Planets are resolved into little discs, like full moons; fixed stars become brighter but remain points.

s. There are innumerable fixed stars invisible to the naked eye, and nebular areas like the Milky Way can be resolved into individual stars.

$\therefore$ Jupiter has four moons.

Galileo argued in Sidereus Nuncius (I6IO) that the Moon is like the Earth (figure 3), as one might expect if Copernicus was right; that fixed stars were clearly much farther away than the planets, as was implicit in

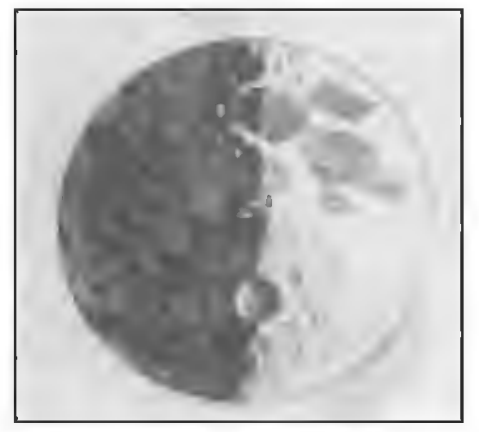

FIGURE 3. Galileo's

observation of the Moon (first quarter). Sidereus Nuncius (Venice, 1610).
Copernicus's theory; that the Earth was by no means the only planet with a moon, and that, regardless of what cosmological system one believed in, there was more than one center of motion in the universe. A few months later he also revealed that the telescope showed that Venus goes through phases, just like the Moon, and, therefore that planet - and by implication Mercury - goes around the Sun. Thus, there were at least three centers of motion: the Earth, the Sun, and Jupiter. These phenomena hardly fitted into the old Aristotelian cosmology, and Venus's phases proved that scheme wrong. But none proved that the Earth moves and the Sun stands still. That proof was centuries in coming. 
Galileo's discoveries were wondrous and new and they were on the tongues of everyone. Since Galileo tied them to the Copernican theory, that theory was now publicly and widely discussed as well. Galileo went on to share the discovery of sunspots in $\mathrm{I} 6 \mathrm{rT}$, and engaged in a public debate-a battle of books - with a German Jesuit named Christoph Scheiner, who argued that the spots are satellites of the Sun, thus saving its perfection. With words, pictures, and diagrams, Galileo showed the Jesuit to be wrong, and came out four-square in favor of the Copernican theory. We all know where this eventually led Galileo and will not follow him there; however, there is one lesser-known discovery that ties him to events later in the century.

In July r6ro, Galileo first observed Saturn with a telescope. To his amazement, the planet showed not a single disk, but rather three: a central one closely flanked by two smaller ones. He thought that perhaps the two companions were satellites, although clearly a different sort of satellite from those of Jupiter (figure 4). ${ }^{1}$ The companions, however, did not move with respect to the central body, and Galileo lost interest for the moment. Two years later, when he was working on sunspots, he again examined the planet and to his surprise found the lateral bodies gone: had Saturn devoured his children? ${ }^{2}$ He discussed this mysterious phe-

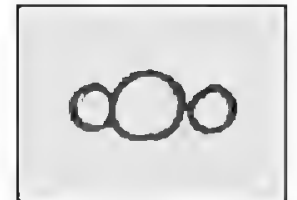

FIGURE 4. Galileo's sketch of Saturn's appearance, July 1610. Le Opere di Galileo Galilei, $x: 410$. nomenon in his sunspot letters and made a complicated prediction of their reappearance. They reappeared as he had predicted, but since they then showed no change he lost interest again; until several years later, in I6I6, he observed Saturn again and found its appearance to be as shown in figure 5. The lateral bodies had grown into two "half eclipses," as he called them. ${ }^{3}$ He could make little sense out of Saturn's appearances, and left them as a puzzle to be solved by his successors.

Telescopic astronomy did not become a regular part of astronomy immediately. For one thing, excellent research instruments-by the standards of the time-are always expensive. But for another, it was not 
immediately clear where the research with this new instrument should be located. It was an optical - that is, mathematical - instrument with

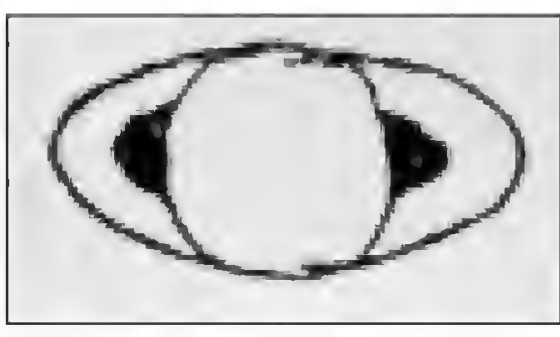

FIGURE 5. Galileo's sketch of

Saturn's appearance, 1616. Opere, XIII: 276 , note 1. which cosmological-that is, philosophicalissues were investigated. Thus, one of Christiaan Huygens's most faithful correspondents, Ismael Boulliau (1604-1696) occasionally observed with a telescope, but for the most part occupied himself in his spare time with astronomical models and tables. The Dibner Library has a letter from Huygens to Bouliau, dated 25 September 1659.

Among a new generation of observers that grew up with the telescope were Pierre Gassendi and Johannes Hevelius. Both these men regularly observed the heavens with their telescopes. And it was after Saturn had once again appeared without its appendages, in 1642 , that they led a generation of observers in a concerted attack on the problem of Saturn. 'Their recorded observations (figure6) give some idea of the results. Given our knowledge, we can easily judge some of these to be better than others, but observers who did not know what caused Saturn's appearances were at a loss. The more so, because a fundamental dichotomy ran through the problem: Ever since Galileo three decades earlier, observers had believed in what we might call a satellite model (see, for instance, figure 7 ), and somehow the "handled" appearance had to be fit into this model. This was a very tall order indeed. It was not until the situation was reversed-that is, the tricorporeal (or satellite) appearance had to be explained in terms of the handled appearance - that proposed solutions came.

The breakthrough came from The Hague, where Christiaan Huygens and his brother Constantijn had begun making telescope lenses in 1654. They quickly progressed to the skill level required to make research telescopes, and Christiaan began exploring the heavens with a 12-foot effort that magnified 50 times, finished in February 1655. By the end of 


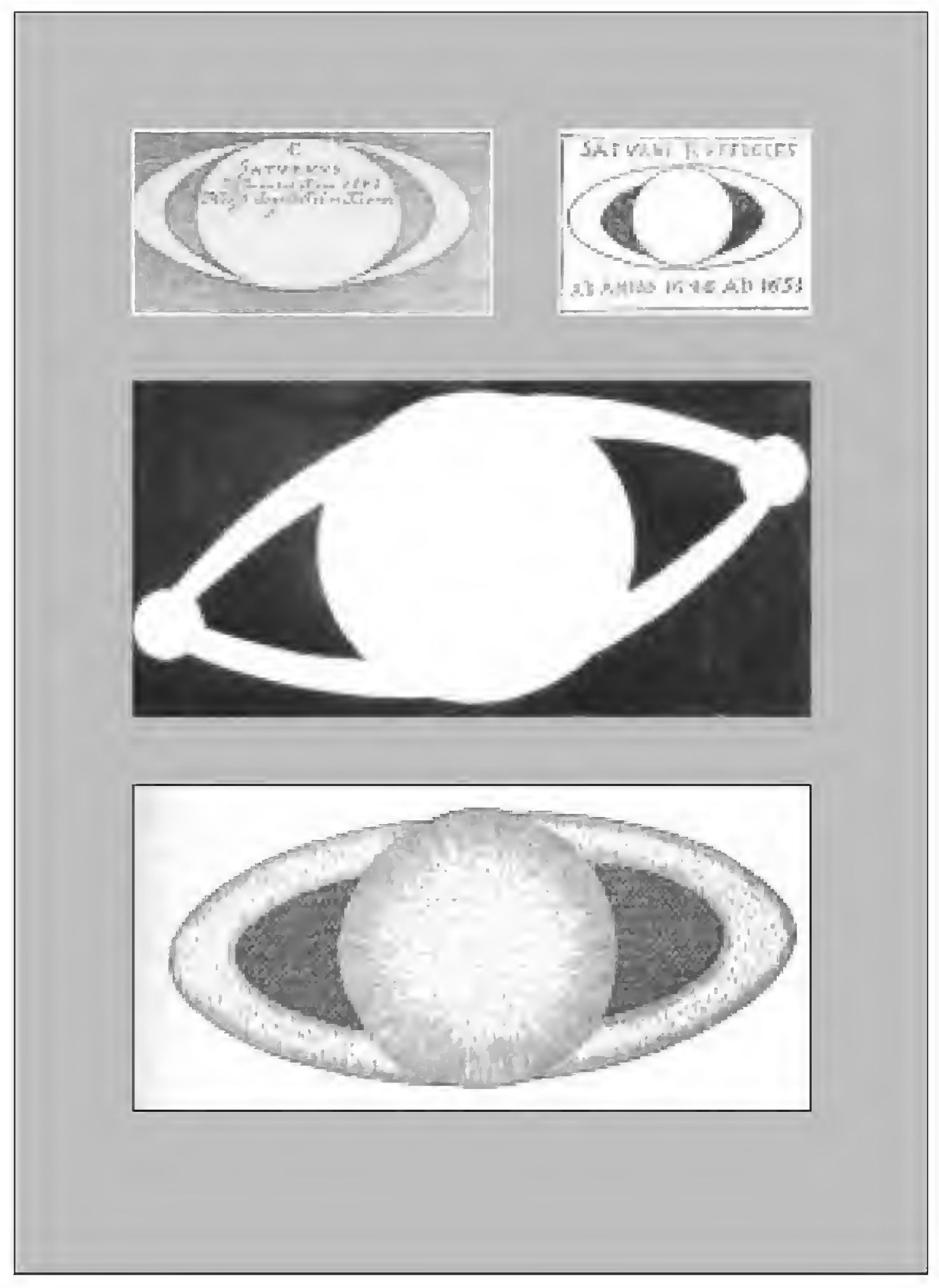

FIGURE 6. Observations of Saturn by: top left, Johannes Hevelius (Selenographia [Gdansk, 1647]); top right, Givanno Batista Odierna (Protei Caelestis Vertigines [Palermo, 1657]); center, Francesco Fontana (Novae Colestium Terrestriumque Rerum Observationes [Naples 1646]); bottom, Eustachio Divini (Broadsheet 1649). 


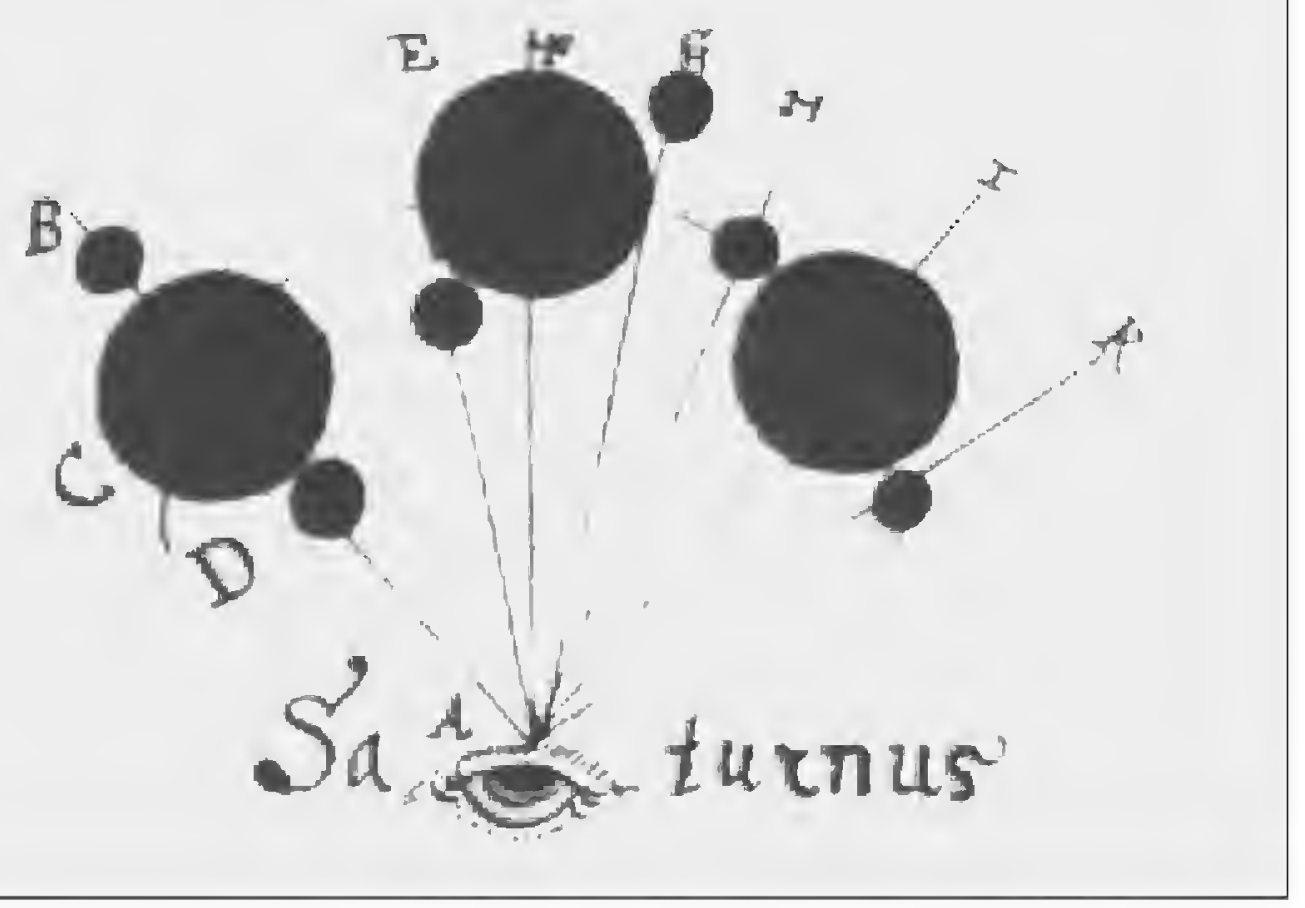

FIGURE 7. Saturn's appearances explained by the satellite model. Christoph Scheiner, "Tractatus de Tubo Optico," Munich, Bayrische Staatsbibliothek MS Clm. 12425, p. 64.

March, he had found a satellite of Saturn. We may ascribe this discovery partly to the quality of his telescope and partly to luck. Over the years, after Galileo's discovery of the four moons of Jupiter, several observers had claimed to have discovered other satellites, either of Jupiter, Mars, or Saturn. Each time, the claims were debunked by other observers. There was perhaps a feeling that, as Wren put it, "all celestial mysteries were at once disclosed to [Galileo]." 4 There was little left for his successors to discover, and it may very well be that no one besides Huygens was looking for satellites. Huygens was lucky because, as the planet's anses were getting thinner and thinner, its moon was behaving more and more like the moons of Jupiter, traveling in a straight line back and forth around Saturn. When the anses form a broader ellipse, the moon describes an oval path around Saturn and is not casily distinguished from nearby fixed stars. 
After observing the moon for several circuits around Saturn, Huygens sent an anagram to a few of his correspondents, a line from Ovid's Fasti with a few extra letters added: Admovere oculis distantia sidera nostris vvvvyvv ccc rr hnbqx. ${ }^{5}$ This, he thought, would safeguard his claim to priority. He then went on a long trip to France, where he told a few scientists of his discovery, returning to The Hague near Christmas I655. At that time Saturn was in conjunction with the Sun, and when it appeared again in January 1656 , the anses had completely disappeared. Some time late in I655 or early I656, Huygens found the solution to the puzzle that had baffled observers since Galileo. An important clue was that the anses did not become shorter as they grew thinner, as we can see from Huygens's earliest surviving observation, made in March I655 (figure 8). He was to explain his reasoning in Systema Saturnium (see p. oo), but for the moment it is important to note that when he solved the puzzle Saturn was either in conjunction with the Sun or completely shorn of its anses. He saw a ring in his mind's eye, not through his telescope.

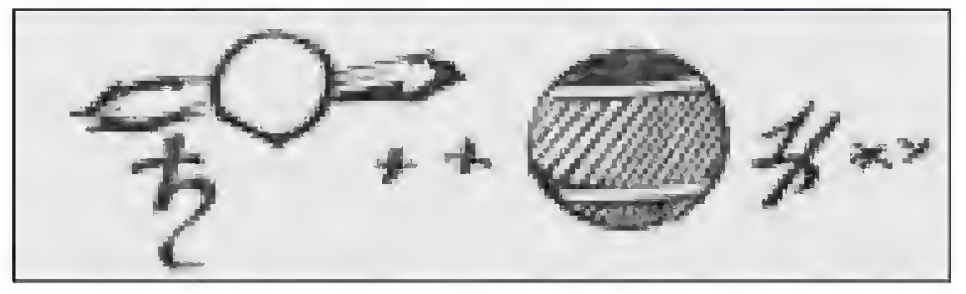

FIGURE 8. Christiaan Huygens's first recorded observation of Jupiter and Saturn, March 1655. Oeuvres Complétes de Christiaan Huygens, I: 322.

While continuing his efforts to make better and better telescopes, Huygens published a brief tract entitled De Saturni Luna Observatio Nova (1656), in which he described his discovery of the new moon and gave an anagram that contained the solution to the problem of Saturn, a a a a a a c c cc deeee hi i i i i i $1111 \mathrm{mmnnnnnnnnooopp}$ $\mathbf{q} \mathbf{r} \mathbf{r} \mathbf{t} \mathbf{t} \mathbf{t} \mathbf{t} \mathbf{t} \mathbf{u} \mathbf{u} \mathbf{u} \mathbf{u} \mathbf{u}$, "so that if perhaps someone may think that he has found the same thing, he will have the time to make it known, so that it will not be said that he borrowed it from us, nor we from him." 6 The complete treatment of the newly discovered moon as well as his theory was, however, not quick in coming. During this period, Huygens man- 
aged to successfully connect a pendulum to a clock and develop the resulting pendulum clock (which improved the accuracy of clocks by an order of magnitude); privileges had to be applied for the clock and the book Horologium (I657) took priority. Then there was also the need to wait for others to come forward with theories concerning Saturn's appearances. And throughout, Huygens continued his observations of the satellite to determine its period more accurately, while simultaneously continuing his observation of the planet and the ring in order to establish the inclination of the ring-plane to the ecliptic and the equator as well as the direction of the major axis of the apparent ellipse of the ring. Systema Saturnium did not appear until the summer of 1659 .

Between the time Huygens found the solution to the problem, in 1655/56, and the appearance of Systema Saturnium, more than three years later (figure 9), others did come forward with their theories. The famous Polish astronomer Johannes Hevelius, for whom establishing the period of the changing appearances was the most important aspect of the problem of Saturn, published Dissertatio de Nativa Saturni Facie in 1656, in which he argued that Saturn consisted of an ellipsoidal central body to which the anses were attached. The entire formation rotated around the minor axis as shown (figure Io). The next year, the Sicilian priest and astronomer Giovanni Battista Odierna published Protei coelestis vertigines seu Saturni Systema (see figure 6 on page 67), in which he theorized that Saturn was an ovoid body with two dark spots on it that rotated on an axis. Meanwhile, the Parisian mathematician Giles Personne de Roberval outlined a rather different sort of theory in a letter to Huygens. According to Roberval, the appearances of the anses were caused by vapors that emanated from a "torrid zone" and collected around Saturn's equatorial plane. When the space above this zone is completely filled with vapors, Saturn appears oval, and when there is space left between the exhalations and the planet's surface, Saturn appears flanked by two "stars." If the exhalations are so thin that they are 


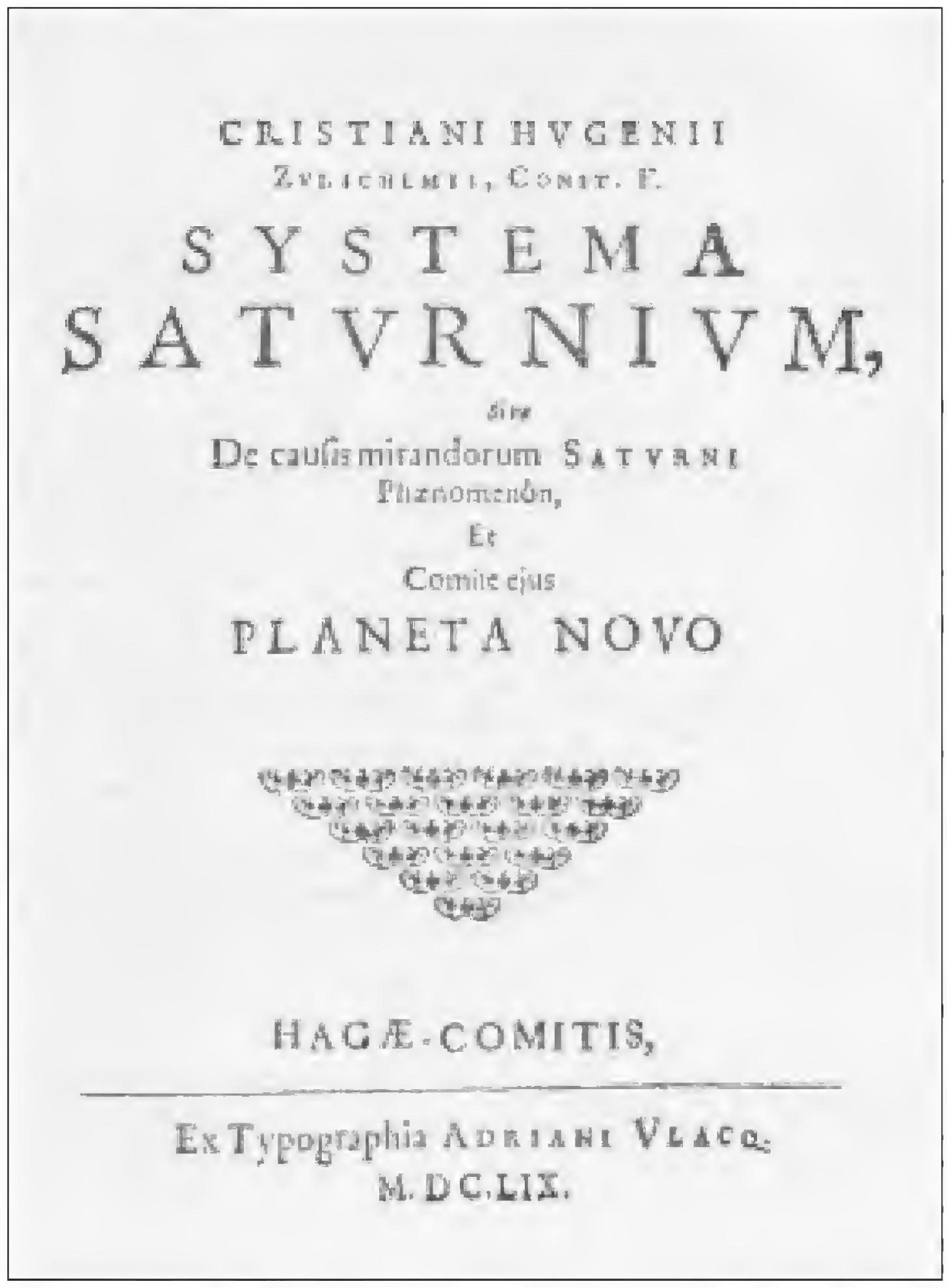

FIGURE 9. Christiaan Huygens's Systema Saturnium (The Hague, 1659). 


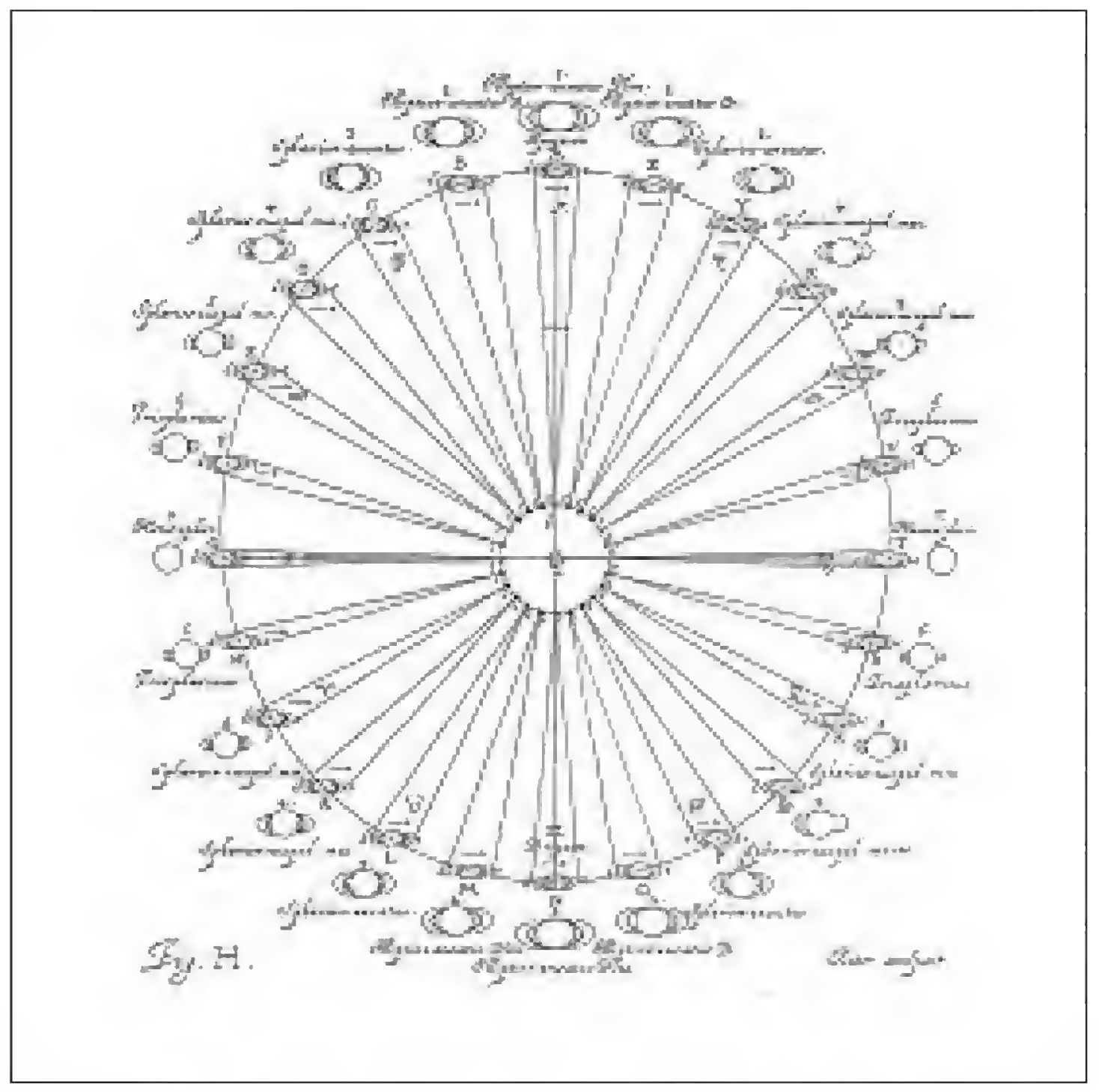

FIGURE IO. Johannes Hevelius's explanation of Saturn's appearances. De Nativa Saturni Facie (Gdansk, 1656).

transparent, the planet will appear round and without its appendages.

By far the most interesting theory, which remained unknown to Huygens until I66r, was developed by the mathematician (and later architect) Christopher Wren. In I658, spurred on by Huygens's challenge and anagram, Wren wrote a little tract entitled De Corpore Saturni. In it he theorized that an elliptical "corona" was attached to Saturn's body (see figure II), and that the entire formation rotated or librated around its major axis. Wren could explain Saturn's appearances reasonably well 


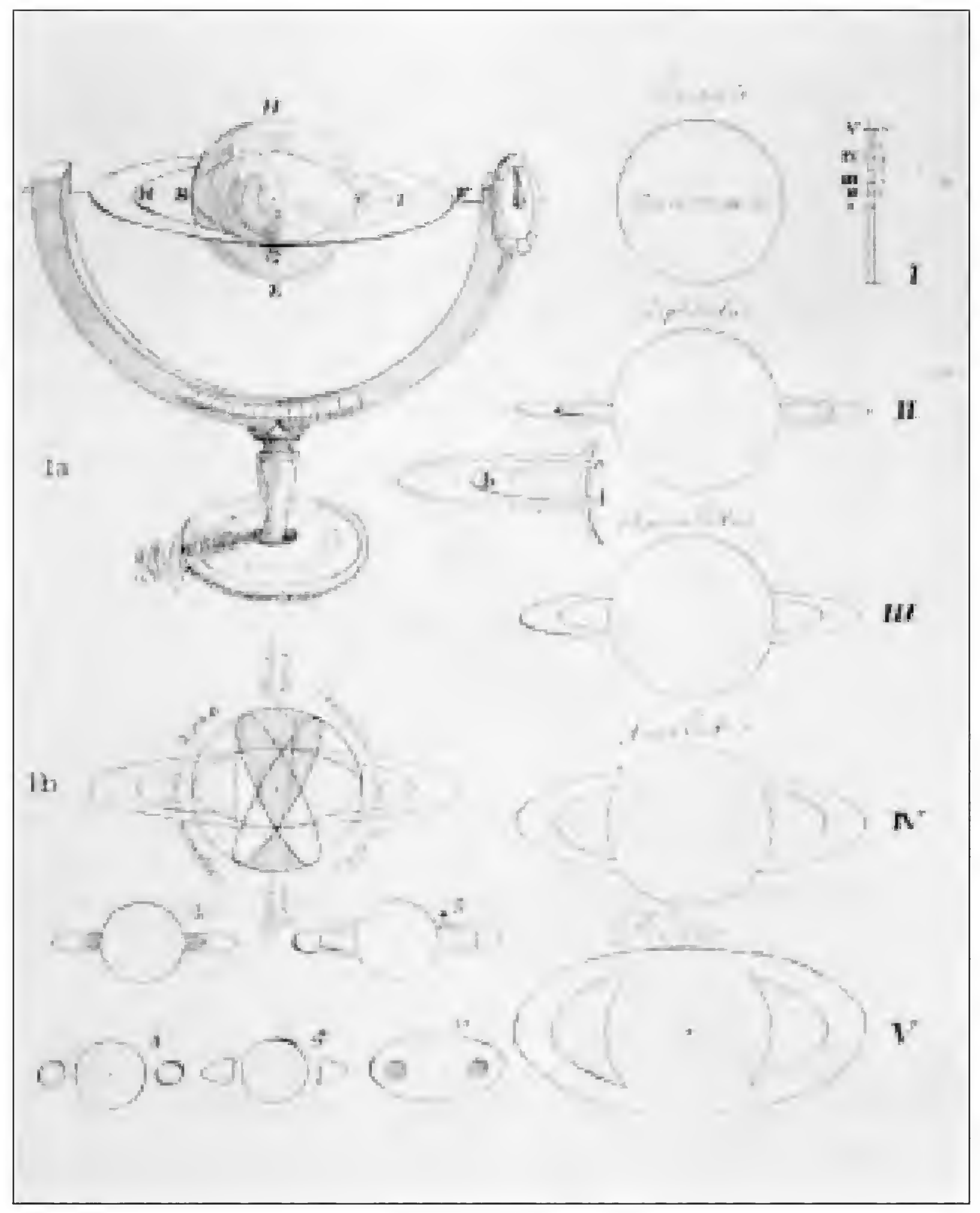

FIGURE 11. Christopher Wren's theory of Saturn's appearances. "De Corpore Saturni," 1658. 
with this hypothesis, and he had an interesting explanation of the fact that this corona periodically became invisible: It had "no sensible thickness, although it is perhaps a few miles thick." Therefore, "[i]ts thickness is not sufficient to be see in any way by the inhabitants of the Earth, and for this reason the corona may be taken as a mere surface." 7

Wren wrote this in 1658 . When, early in 1659 , Huygens informed his English colleagues of his ring-theory, Wren put the manuscript away. When he was asked about his theory a few years later, he explained why he had not pursued it further:

... when a shorte while after, the Hypothesis of Hugenius was sent over in writing, I confesse I was so fond of the neatnesse of it, of the Naturall Simplicity of the contrivance agreeing soe well with the physical causes of the heavenly bodies, that I loved the invention beyond my owne d though this [hypothesis] be so much an equipollent with that of Hugenius, that I suppose future observations will never be able to determine which is the trewest, yet I would not proceed with my designe... ${ }^{8}$

In the summer of 1659 , Systema Saturnium finally appeared. Huygens had already explained his ring-theory to his French and English colleagues by this time, but if expectations of the book were high, the reader was not disappointed: In sheer amount of celestial novelty Systema Saturnium rivaled Galileo's Sidereus Nuncius published half a century earlier. Huygens described his telescopes, showed observations of the belts and zones of Jupiter (observed earlier by others), details on the surface of Mars, and the Orion nebula (missed by Galileo) with three of the four stars now known as the Trapezium. Huygens then turned his attention to Saturn. He first discussed all his observations of the new moon made over a period of four years and derived its period. Then he discussed Saturn's appearances published by others, beginning with Galileo, explaining away or rejecting appearances that would not fit the hypothesis he was about to put forward. Only after this process did he come to his ownexplanation of Saturn's appearances. 
Huygens explained how he arrived at the ring-hypothesis. Our Earth spins on its axis once a day, while the Moon goes around us once a month. By analogy, if Saturn's moon has a period of sixteen days, then the planet must spin on its axis in a much shorter period. And this means that all the matter between Saturn and its moon must rotate around that same axis in times intermediate between $\mathrm{I} 6$ days and perhaps a day. Although Huygens does not say this, the influence of René Descartes (who visited the Huygens family home several times) is apparent: Huygens was thinking in terms of vortices. All planets are at the centers of their own sub-vortices, while they all go around the Sun in one big vortex. But that meant that the anses, whatever their shape, had to revolve around Saturn's axis of rotation with a very short period. Changes in their appearances, however, happened very slowly, with a period of about I4 years, not in a few days. The anses therefore had to be symmetrical about Saturn's axis of rotation; a ring satisfied that requirement. At this point, Huygens presented the solution to the anagram he published three years earlier in De Saturni Luna Observatio Nova: annulo cingitur, tenui, plano, nusquam cohaerente, ad eclipticam inclinato, or "It is surrounded by a thin, flat ring, touching it nowhere, and inclined to the ecliptic."'

The next order of business was to establish certain parameters, such as inclination of the ring-plane to both the equator and ecliptic. He made the ring roughly parallel to the plane of the (Earth's) equator and placed its intersection with the ecliptic at $20_{-}{ }^{\circ}$ Pisces and Libra. Having determined these points, he could explain when and where the ring could give rise to all the appearances observed over the years (figure i2), with the exception, of course, of those that were the result of primitive telescopes or observer error. Predicting when and in what part of the zodiac the ring would again be invisible was straightforward. But why the ring should be invisible was, for Huygens, rather tricky, because he believed the ring to be a solid structure which, although comparatively thin, was nevertheless several thousand miles thick. When the ring was edge-on it 


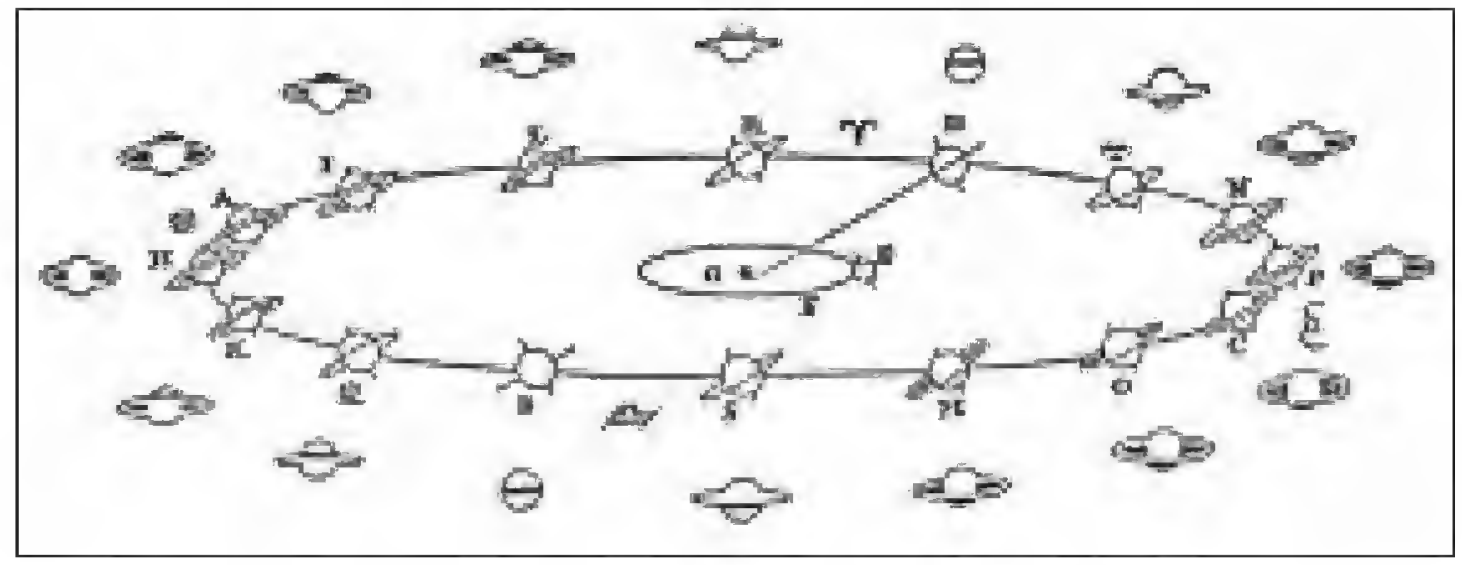

FIGURE I2. Huygens's diagram to explain Saturn's appearances.

Oeuvres Complètes, xv: 309.

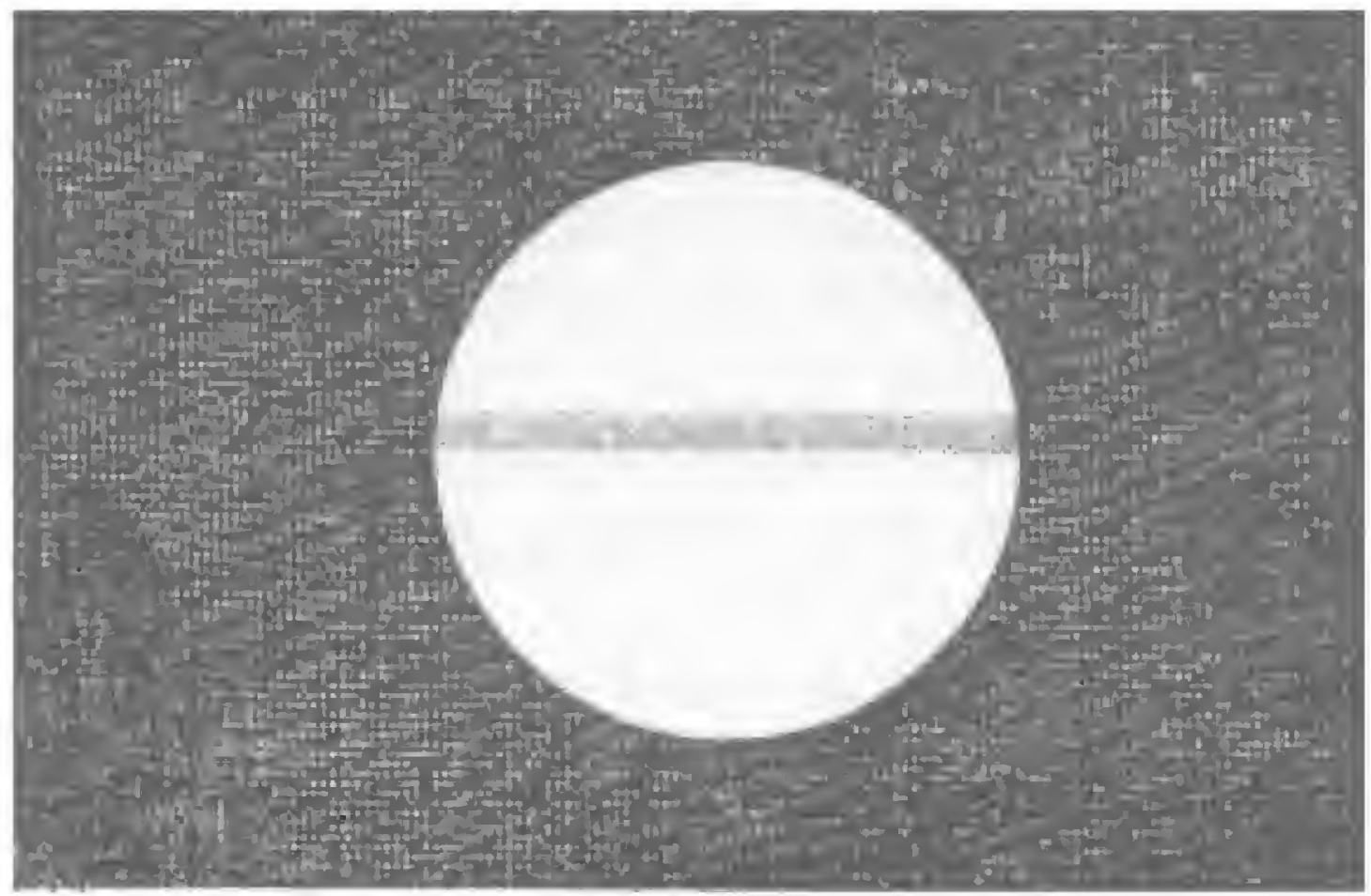

FIGURE 13. Hiygens's observation of Saturn in the winter of $1655-56$, when the anses were invisible. The dark line, which is the shadow of the ring on the planet's body, was interpreted by Huygens as the dark exterior edge of the ring. Oeuvres Complètes, Xv: 247. 
was invisible, Huygens argued, because its outside edge was covered with a material that did not reflect light. He interpreted the dark line he had seen across Saturn's disc during the round appearance of I655-56 (figure I3) as the ring's dark outside edge.

Huygens ended Systema Saturnium with an important digression on the sizes and distances of the planets: How would the solar system appear to an inhabitant of Saturn? For the answer, he needed to know the absolute sizes and distances of the planets. First, he explained how one could measure a planet's angular diameter. In the "astronomical" telescope used by Iuygens, one with a convex eyepiece, the rays come to a focus inside the tube. If one places an object in the focal planet, it will appear in focus and superimposed on the image of the object one is observing. Huygens put an aperture stop in this plane, measured its angular size by timing the progress of a star across it (while holding the telescope fixed) - he found it to be 17 _ minutes of arc — and then, when he observed a planet, he would insert thin copper rods into the focal plane until he found one that just covered the planet's disk. Knowing what fraction of the aperture was covered by the thickness of the rod, he could easily determine the angular diameter of the planet. Now, the first fullfledged micrometer had been made by William Gascoigne in England two decades earlier, but it was still unknown to the astronomical community. Huygens here published the principle of the micrometer, and the wire micrometers made in the next decade by French astronomers were the result of this passage in Systema Saturnium.

Having measured the angular diameters of all planets except Mercury, and knowing the relative distances of the planets from the Sun, Huygens now knew how large the planets were with respect to the Sun. He needed one absolute measure to turn all relative sizes and distances into absolute ones. There was, as yet, no way to make such a measurement, so Huygens made an argument from harmony. The sizes of the planets roughly increase with their distances from the Sun, except that Huygens 
found Jupiter to be larger than Saturn and Venus larger than Mars. Nevertheless, he assumed the Earth to be intermediate in size between Mars and Venus. Since Mars's diameter was I/166TH part of the Sun's and Venus I/84TH part, Huygens took the mean between these two fractions and arrived at a terrestrial diameter I/IIITH the Sun's-an "accurate guess." This meant a solar distance of about 25,000 terrestrial radii, or, in modern figures, roughly roo million miles. This corresponds to a solar parallax of $8.2^{11} \cdot{ }^{10}$ Huygens now had a complete scheme of sizes and distances in the solar system, and shortly after Systema Saturnium had appeared, he found a way to present his results visually (figure 14).

Systema Saturnium was then, a book about much more than just the problem of Saturn, but it was about Saturn that he received most criticism. No single construction of the anses could account for every single appearance of the planet found in the literature, and Huygens had therefore criticized and dismissed a number of them. But how could he justify his judgments? He argued:

In this investigation, we ask that it is conceded that, because we were the first to detect the companion of Saturn with our telescopes and clearly see it whenever we wish, therefore our telescopes must be preferred to those of others who, although daily engaged in observing Saturn, were nevertheless unable to reach that star; and that therefore the results of our observations of the shape of the planet must be judged to be truer each time when the different shapes were simultaneously observed by us and by them. ${ }^{11}$

This was a clever argument, and Huygens may have believed it himself. For those with mediocre telescopes it was undoubtedly true, but to observers whose telescopes were among the best in Europe - and whose reputations were based on the excellence of their instruments-Huygens's claim was an insult and a challenge. For them there was a difference between not having observed Saturn's moon earlier and not having telescopes good enough to show it. Johannes Hevelius pointed out that he had observed the satellite a decade earlier but had taken it to be a fixed 


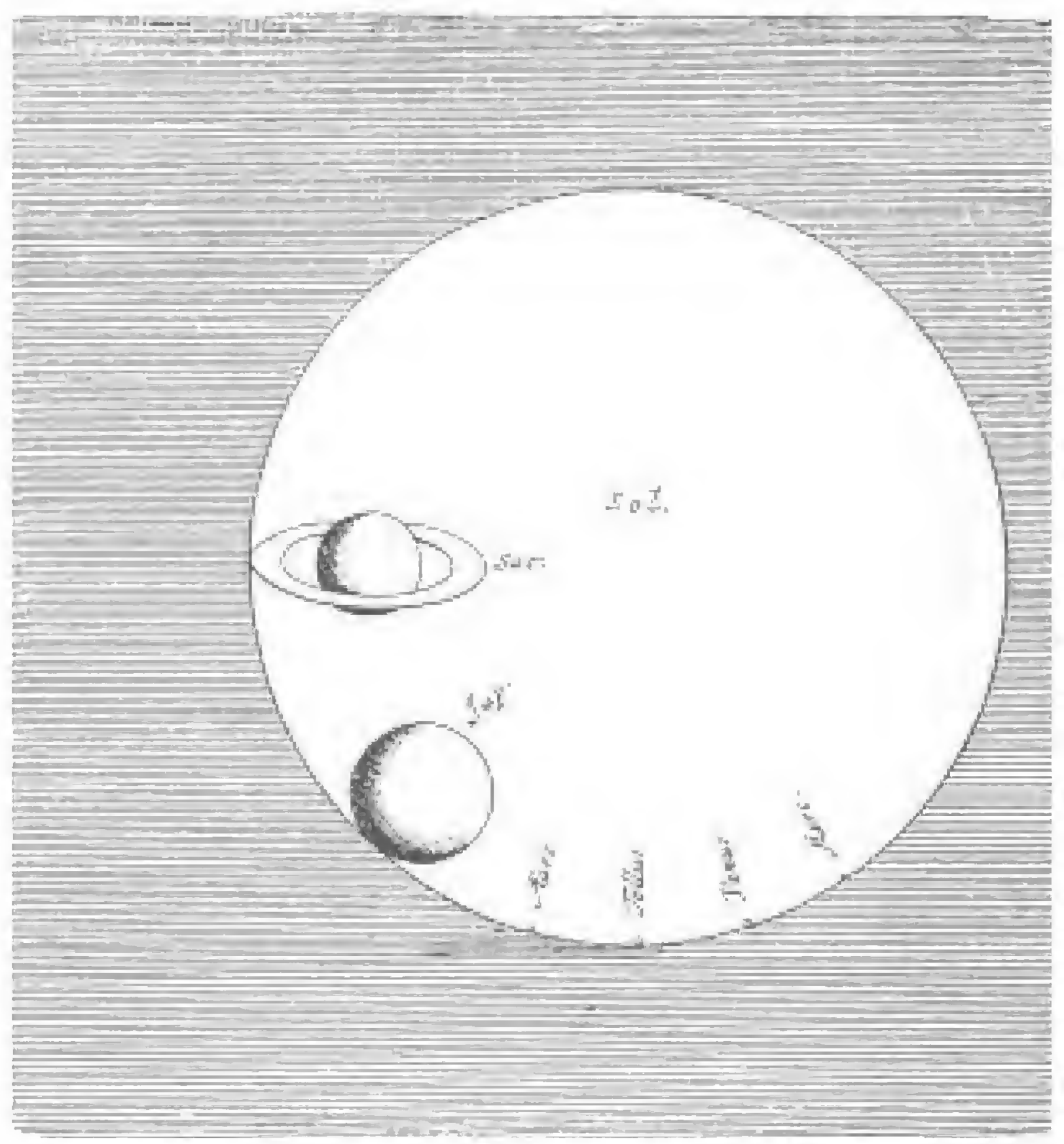

FIGURE I4. Hinygens's representation of the sizes of the planets relative to the Sun.

Oeuvres Complètes, Xv: 374. 
star. As he wrote to his friend Ismael Boulliau, "And therefore I see no reason why our observations do not merit the same faith as those of Huygens."12 His telescopes were just as good as those of Huygens, and as far as his eyesight and his claim that Saturn's central body was ellipsoidal was concerned: "[D]oes Huygens perhaps suppose that I and others cannot see the difference between elliptical and spherical, or that it was invented by my mind... or rather that I dreamed it? No, by Hercules!" 13 But having vented his rage to Boulliau, Hevelius expressed his disagreement to Huygens himself in very measured tones. Their relations remained cordial.

An entirely different approach was taken by Eustachio Divini (I6I51675) in Rome, considered by many to be the finest telescope maker of Europe. Huygens had criticized Divini's illustration of Saturn published in 1649 (see figure 6 on page 67) not for its shape, but for the spurious shadow effects: "Since he is considered a most excellent telescope-maker, it is credible that he has described the actual shape of Saturn best of all, except for the shadows that appear in the figure which, in my opinion, were added by him." 14 This statement was hardly a criticism, and Divini easily could have blamed the problem on the engraver. But Huygens's claim of authority was another matter. Divini had won his eminence in his trade by great skill and hard work, taking on all challengers. His best telescopes were among the collection of instruments of the Florentine Accademia del Cimento of Grand Duke Ferdinand II and his brother Prince Leopold. It was to Leopold that Huygens had dedicated Systema Saturnium, and thus Huygens's authority claim was all the more serious for Divini: Was he no longer the best telescope maker in Italy, or Europe?

But in Rome there were other problems (or rather opportunities?) raised by Systema Saturnium and its author. As a Dutchman, Huygens was a Calvinist heretic, and moreover in his book he took the centrality of the Sun as given. And therefore, if Divini wanted to strike a blow against Huygens's pretensions as a telescope maker, the Jesuit Honoré Fabri saw 
an opportunity to raise the cosmological issue. Together they composed (but published with only Divini's name on the title page) Brevis Annotatio in Systema Saturnium Christiani Hugenii (Rome i660), likewise dedicated to Prince Leopold. Divini argued the superiority of his telescopes-he, too, could easily see Saturn's moon-and Fabri attacked Huygens's Copernicanism while proposing another explanation of Saturn's manifold appearances. He supposed a satellite model in which two sets of satellites, one pair light-absorbing and the other light-reflecting, revolved about points behind Saturn, (see figure 15). Divini (and Fabri) stated that they "eagerly submitted their ideas to [Prince Leopold's] very just censure and clear judgment." 15

These two books put Prince Leopold in an awkward position. On the one hand, there was an elegant hypothesis put forward by a heretic and Copernican; on the other, there was a rather silly hypothesis put forward by a member of a powerful order committed to preserving the Christian-Aristotelian cosmology. The Galileo process of I633 had power-

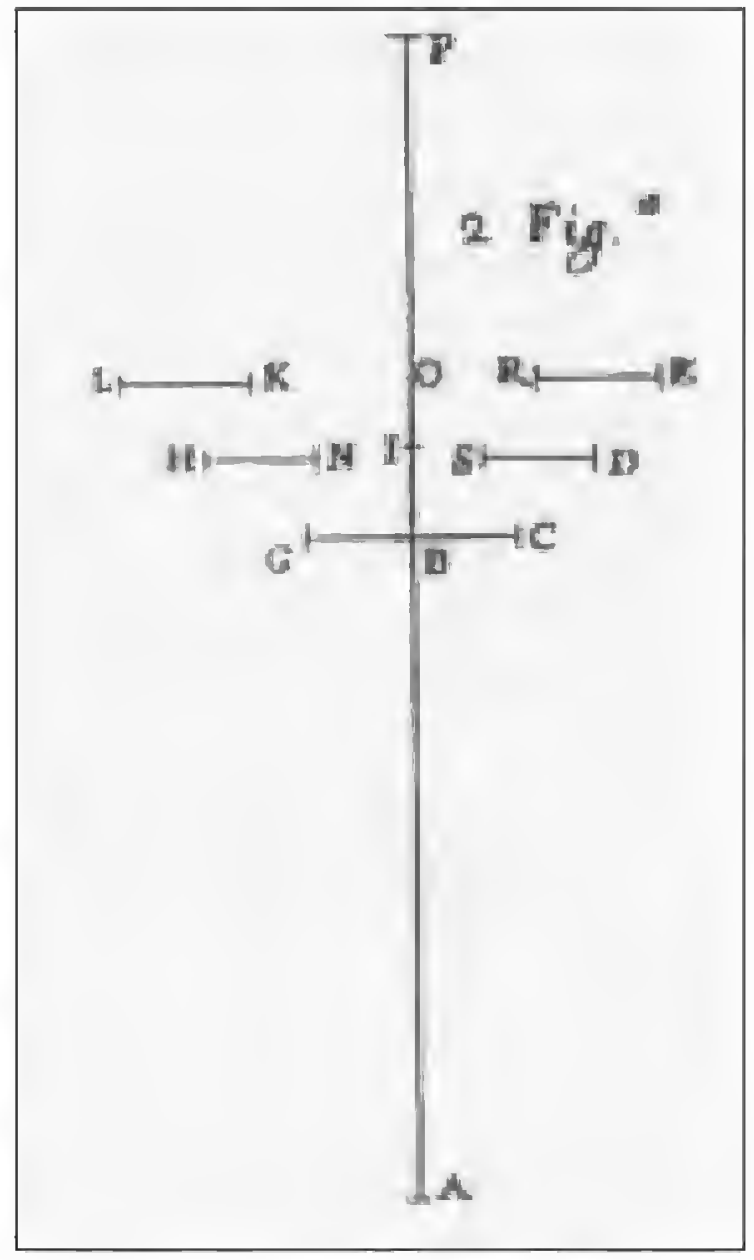

FIGURE 15. Honoré Fabri's explanation of Saturn's appearances, from Eustachio Divini's Brevis Annotatio in Systema Saturnium (Rome, 1660). GC represent's Saturn, HN and $S D$ light-absorbing satellites, and $L K$ and $R E$ light-reflecting satellites. fully demonstrated the end to Florence's power to thumb its nose at Rome, and in Fabri's text, several instances seemed directly to refer to the Galileo affair. In explaining Fabri's hypothesis, Divini (sic) began with the following proposition: "The Earth is immobile at the center of the world and the celestial spheres revolve around it. This is an opinion that 
he defends with tenacity, judging it as conforming to Catholic decrees, to Sacred Scripture, to the observed phenomena, and to sane reason." 16 And as if to once more drive home the restricted authority of the mathematician in cosmological matters, Fabri let it be known that he did not defend his model as a true explanation of Saturn's appearances, but rather held it "only as one hypothesis of many that can save the appearances hitherto observed by the Astronomers." 17

Prince Leopold and his academy found a neat way out of their dilemma. Following the Accademia del Cimento's motto, provando e riprovando "to test and test again," they decided to settle the issue experimentally. Models of both hypotheses were built, and these were observed from various distances with the naked eye and telescopes of various powers - and not only by scientists, but also by people who had no idea what they were looking at. The results of these comparisons were clear. The model of the ring hypothesis (figure 16) could produce the socalled "trispherical" appearance that Galileo had first seen, but the model of Fabri's "satellite" hypothesis could in no way produce the "handled" appearance. In one respect, however, Huygens's ring could not bear away the approval of the academicians. Since they could not think of "any example in Nature of a material so unapt for the reflection of light," they were reduced to making the ring as thin as possible and thoroughly removing all roughness of its surface, for even surface irregularities that were, in proportion to the model any higher than the highest mountains on Earth would be seen as in thin bright line when the ring was in the edgewise aspect.

Reports were sent to Huygens and Fabri, with an admonition from Prince Leopold to keep them confidential. At the same time, Huygens published a rebuttal to Divini and Fabri, entitled Brevis Assertio Systematis Saturni sui, ${ }^{18}$ which he issued together with a reprint of Brevis Annotatio (I660), and his correspondents congratulated him on showing up the foolishness of the Roman telescope maker. The next round from 


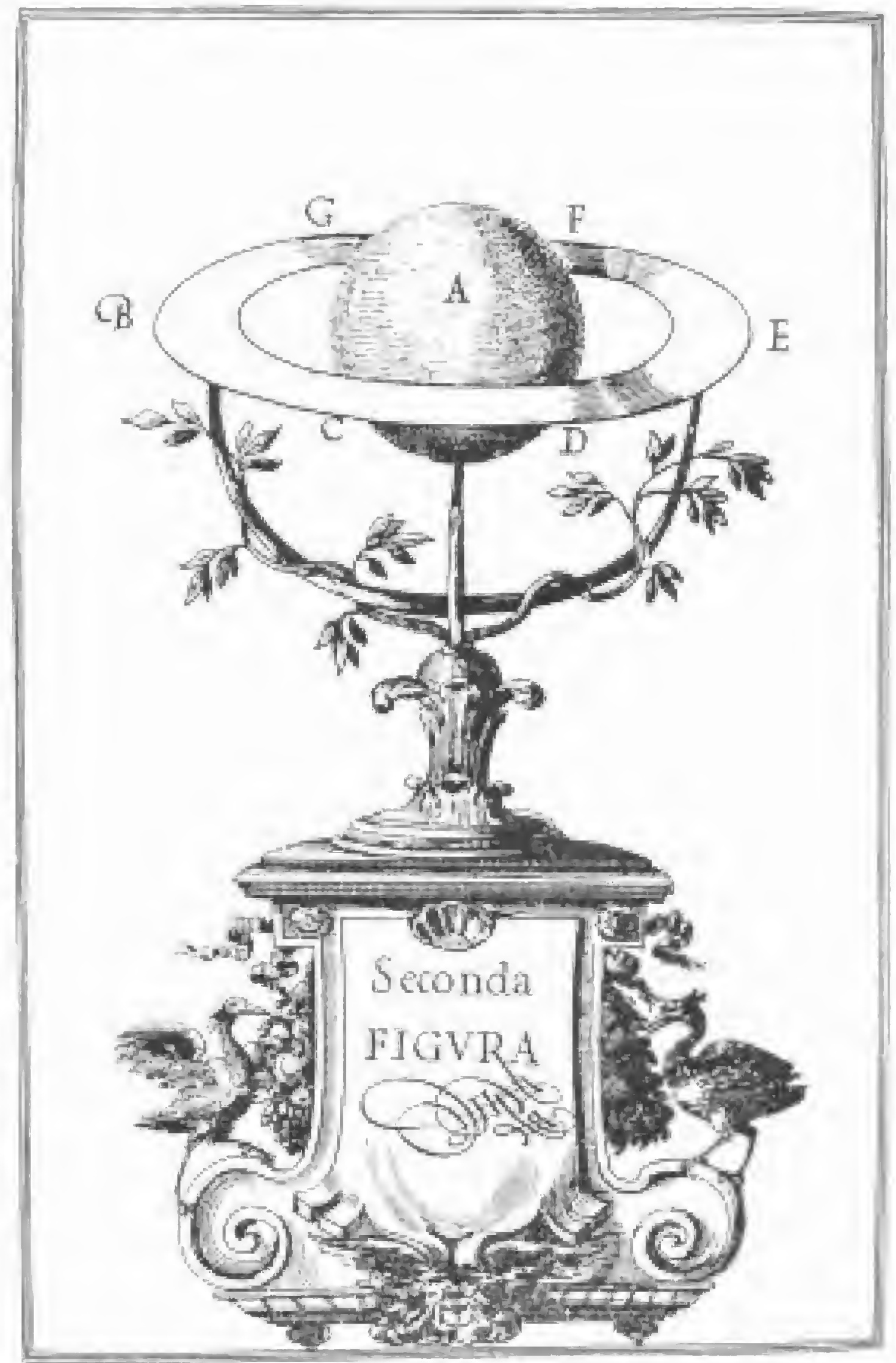

FIGURE I6. Model of Huygens's ring-theory made by the Accademia del Cimento. Oeuvres Complètes de Christiaan Huygens, vi: 000. 
Rome, Pro sua Annotatione in Systema Saturium Christiani Hugenii (Rome I66I) did not deserve a reply. Fabri here had added two further lightreflecting satellites behind Saturn in order to more closely approximate the planet's handled appearance, but clearly things were getting silly. The more so because Divini/Fabri admitted that he could not help seeing a ring when he now observed Saturn. Huygens had clearly won the argument, Prince Leopold had retained his neutrality, and Fabri went on to other challenges. 'The big loser was Divini. For one thing, in making actual observations of Saturn, the academicians in Florence had used a long telescope by Divini, and had found the objective lens inferior. They had taken it out and substituted an objective made by Evangelista Torricelli made more than a decade earlier. And with that combination, they had for the first time observed the shadow of the ring on Saturn's bodya powerful confirmation of the correctness of Huygens's theory. Worse was to come for Divini. In 1662, a mysterious telescope, said to be made in the Netherlands, began to be shown in Rome and proved to be better than any instrument made by Divini. This was the first move in a carefully choreographed campaign by Giuseppe Campani and his brothers to undermine and ridicule Divini on his own turf. They succeeded: By I665 Campani had replaced Divini as Europe's premier telescope maker. If Huygens had defeated the telescope maker Divini and the scholar Fabri with comparative ease, telescopes by Campani in the hands of the astronomer Giovanni Domenico Cassini would, as we will see, prove to be a more formidable challenge. For the time being, however, Huygens ruled supreme as a telescopic astronomer. He had made the first addition to the number of bodies in the solar system since Galileo, and solved a problem first posed by Galileo with a breathtakingly elegant solution, accepted by everyone in short order; although the parameters, the relative diameters of the ring and body, and the inclination of the ring plane to the ecliptic and equator had to be adjusted and Huygens's explanation of the ring's invisibility when its plane passed through the Earth was not 
generally accepted. On the basis of his mathematical work, his telescopic astronomy and his invention of the first successful pendulum clock, Huygens was invited by Jean Battiste Colbert, Louis XIV's minister, to become a member of the newly founded Académie Royale des Sciences and give it intellectual leadership. When he moved to Paris in I666 to take up the appointment, he was perhaps Europe's most famous scientist.

Giovanni Domenico Cassini (1625-1712) was born in Perinaldo in Liguria, and educated in a Jesuit college in Genoa. ${ }^{19}$ Because of his brilliance, he attracted the attention of powerful patrons, and in I649, at the age of 25 , was appointed to the chair of astronomy at the University of Bologna. Here he was influenced by Giovanni Battista Riccioli, professor at the Jesuit College, who was completing his massive Almagestum Novum (Bologna, 1651), a complete review of astronomy. Cassini quickly learned what the burning issues in technical astronomy were, and he attacked several of these. The meridian laid down in the cathedral of San Petronio by Egnatio Danti in the sixteenth century had fallen into disrepair, and Cassini completely rebuilt it. The result was the meridian (or gnomon) much the way we still see it today. Cassini's achievement was one of the centerpieces of the celebration surrounding the arrival of Queen Christina of Sweden, who passed through the city on her way to Rome in I656. But Cassini also made careful measurements. Upon comparing solar declinations measured on the meridian with his measurements of the altitude of the Pole, he found a discrepancy of 2 arc-minutes. He concluded that this discrepancy was due to faulty positional corrections for atmospheric refraction and solar parallax, and this meant that the value for the obliquity of the ecliptic given by the great Tycho Brahe might be in error by two arc-minutes $\left(2^{\prime}\right)$ - an error that affected not only position measurements, but also the theories of all the planets. This became an important part of Cassini's research agenda, and he was to return to the problem again and again. For the time being, he made his new positional corrections part of a new set of tables published in I66I. 
Cassini's hard work, organizing ability, and political acumen were rewarded with preferments. The Pope, overlord of Bologna, appointed Cassini inspector of papal fortification and then also as his engineer to look after the papal interests in the eternal arguments about water rights and the courses of rivers between cities in the Po valley and between the Papal states andTuscany. In these capacities, Cassini traveled a great deal and often was in Rome. He was there in 1664 when Giuseppe Campani challenged Eustachio to a paragone (comparison) to decide whose telescopes were better. Cassini took part in these trials, and if the immediate results showed that Campani telescopes were better than those of Divini, Cassini's personal preference for Campani telescopes was one of the decisive factors in Campani's lasting fame. In Rome, in I664, Cassini and Campani made a series of telescopic observations, published in a little book entitled Ragguaglio di due nuove osservazioni and a broadsheet showing observations of Jupiter and Saturn. The most remarkable of these showed shadows of Saturn's ring on its body and vice versa, the fact that the outside of the planet's ring was darker than the inside, and the shadows of Jupiter's satellites on Jupiter's body. With these publications, Campani's fame rapidly spread to all parts of Europe where there was interest in astronomical observations.

Over the next several years, as his duties took him to many places in Italy, Cassini made observations with a I7-foot Campani telescope, an instrument given him by the maker himself. With this very fine instrument, he observed the planets whenever possible, including the formation of Jupiter's satellites and their immersions in, and emersions from Jupiter's shadow. The result was an important series of publications, the most important of which were two works on, respectively, surface markings and the rotation periods of Jupiter and Mars, and a set of tables of the motions of Jupiter's moons. ${ }^{20}$ Cassini's reputation was rapidly growing (figure I7), and when Colbert began looking for an astronomer to lead the new observatory that was being designed by Claude Perrault, 


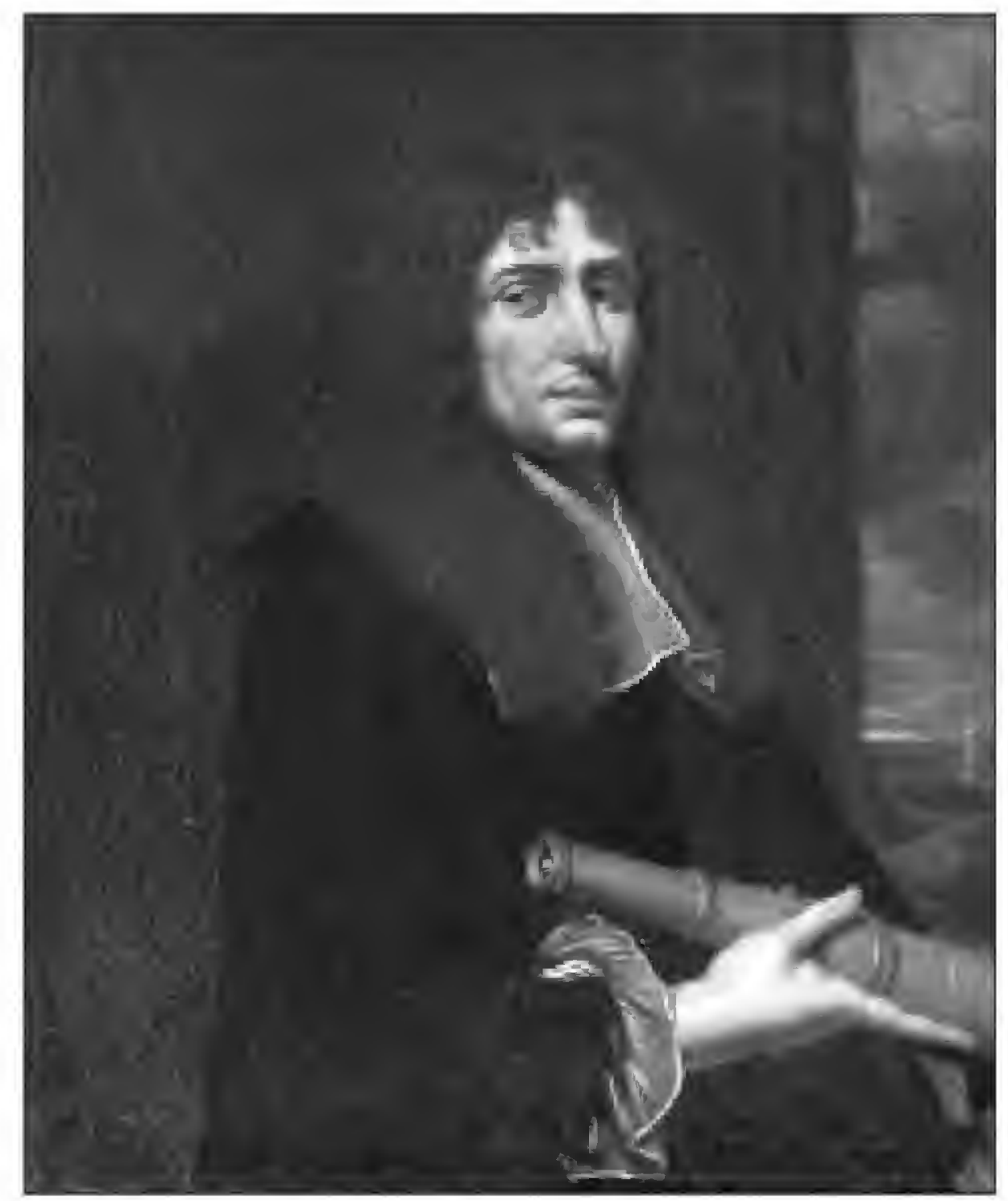

FIgure 17. Portrait of Giovanni Domenico Cassini, ca. 1665-1669. Ventimiglia, Biblioteca Aprosiano.

his eye naturally fell on Cassini. But getting the Pope's astronomer to Paris was by no means an easy task. Through diplomatic channels, Colbert let it be known in Rome that "His Most Christian Majesty has expressed the desire to have Mr. Cassini there [Paris] for some time. ${ }^{21 "}$ After some negotiations, His Holiness let Cassini go, and he arrived in Paris in 1669 to start a new chapter in his life.

Cassini quickly made his influence felt in Paris. Modifications were made to the (as yet unfinished) observatory; to make it more suitable for 
astronomical observations, he ordered powerful telescope lenses from Campani in Rome; and he intervened in the plans for an astronomical expedition to the tropics. His first major success was the detection of two new moons of Saturn during the ring's edgewise aspect of i671-72 (satellites now called Iapetus and Rhea). The expedition to Cayenne by Richer (1763), it is well-known, resulted in the discovery that a pendulum of a given length has a shorter period in the tropics than at mid-latitudes. But at the time it was more important that by measurements of solar declinations Richer proved that Tycho Brahe had indeed made an error of two entire arc-minutes $\left(2^{\prime}\right)$ in the obliquity of the ecliptic. Also during this expedition, while taking advantage of a favorable opposition of Mars, Cassini's simultaneous measurements of the planet's positions in Europe and Cayenne led to a downward adjustment of solar parallax to about ten arc-seconds ( Io $^{\prime \prime}$ ), a value Cassini had been advocating for some time because it led to a better combination of corrections for atmospheric refraction. ${ }^{22}$

In the meantime, Cassini had sent Jean Picard to Uraniburg, the remains of Tycho Brahe's observatory, to check the latitude and longitude of that observatory, so that Tycho's observations could be referred to the coordinates of Paris. For these observations, simultaneous observations of the eclipses of Jupiter's satellites were used. With a view to correcting the large errors in positions of faraway places, Cassini over time established a worldwide network of correspondents who sent him observations of Jupiter's satellites. 'This is not to say that errors nearer home were not equally troublesome. Jean Picard had published his Mesure de la Terre in I67I, which established the length of a degree at the latitude of Paris, but the locations of cities in France still left a lot to be desired. Wherever Cassini and his astronomers went in France, they observed the eclipses of Jupiter's satellites, and slowly the contours of France were corrected to a point where a revised map of France (not finally published until I693) made adjustments of a full degree on France's Atlantic coast 
and half that much to its Mediterranean coastline. ${ }^{23}$ Legend has it that upon seeing this new map Louis XIV complained that he was losing more territory to his astronomers than to his enemies. Si non è vero è ben trovato. With Campani telescopes, Cassini discovered the division in Saturn's ring in 1676 (figure 18 ), and during the next edgewise aspect of Saturn's ring he discovered yet two more moons of the planet (now called Tethys and Dione).

Huygens's career at the Académie was not as happy. In $167 \mathrm{I}-2$, at the time when his portrait

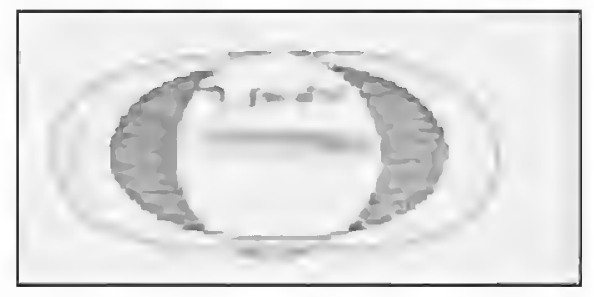

FIGURE 18. Cassini's observation of the gap in Saturn's ring, now called Cassini's Division. Journal des Sçavans, 4 January 1677. was painted by Caspar Netscher (fig I9), he had to return to The Hague to recover from a bout of melancholia; in I673 he published his opus magnum, Horologium Oscillatorium, dedicated to the Sun King at a time when France (along with several other countries) was at war with the Dutch Republic. In 1675 he once again had to absent himself for more than a year because of melancholia, and in $\mathrm{I} 68 \mathrm{I}$ he again returned to The Hague with the same affliction. That time, however, his return to Paris was more difficult, as the tide was running against the Protestants in France. The death of Colbert in 1684 and the repeal of the Edict of Nantes the following year eventually made his return impossible. So, as Cassini went from victory to victory, Huygens faded away. The confident Cassini with his Campani telescope, who came in I669 had turned into the brilliant astronomer of a decade later; who by gesture claimed the observatory as his own (see figure 20). He was the brilliant courtier who could have the water tower of Marly moved to the grounds of the observatory in order to accommodate the very long "tubeless" telescopes with which he continued his amazing series of discoveries. Cassini married at the age of fifty and trained his only son to become his successor as director of the observatory. He brought a nephew on his mother's side, Giacomo Filippo Maraldi, to join the staff of the observatory. In 1794-95, Cassini 


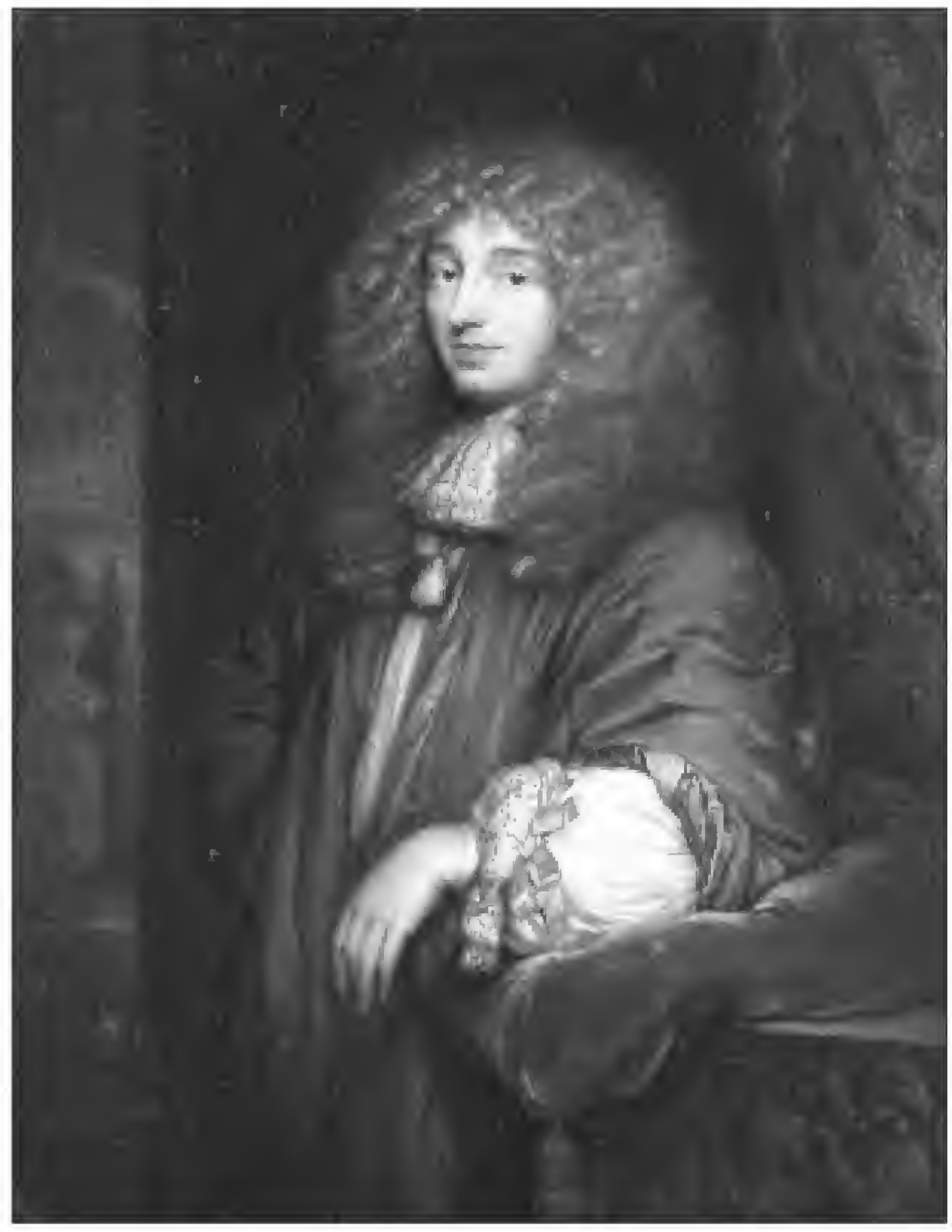

Figure 19. Portrail of Huygens by Caspar Netscher, ca. 1671. The Hague: Haggs Historisch Musetum. 


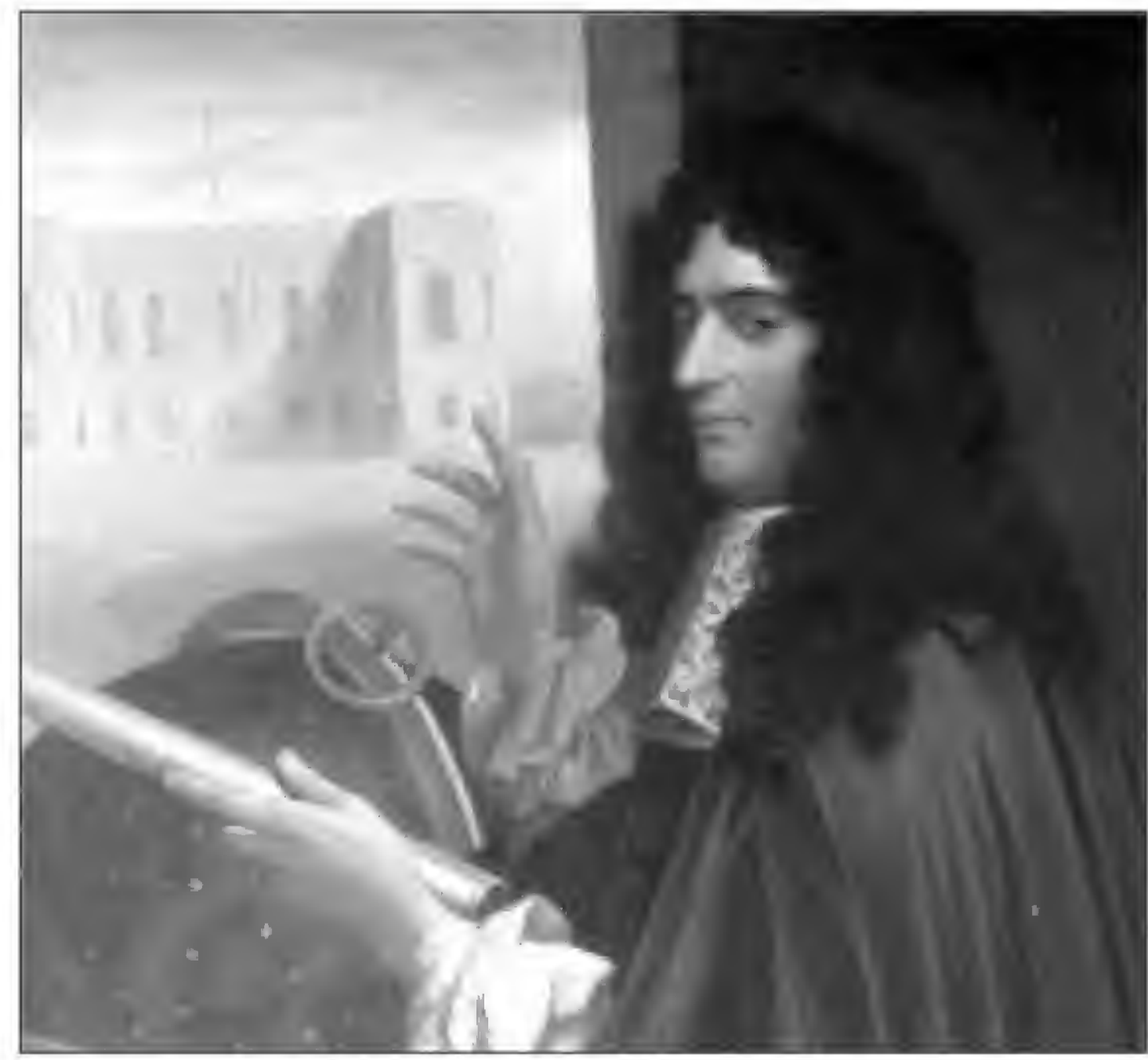

figure 20. Portrait of Cassini ca. I675

(provenance to follow)

undertook a trip to Italy, where he updated the meridian of San Petronio in Bologna. It was a veritable victory tour for the most powerful scientist in Catholic Europe, progenitor of four generations of Cassinis, who ran the French observatory until the French Revolution.

Huygens fades somewhat in this comparison. But although it certainly is true that Cassini, the brilliant courtier and energetic organizer, outshone Huygens at the French Court, it is equally true that Huygens was the more profound thinker and brilliant mathematical scientist. When a systematic error was discovered in the times of the eclipses of the first satellites of Jupiter, the period of which was equal to Jupiter's 
synodic period, Danish astronomer Ole R¿mer, visiting astronomer at the Paris observatory, interpreted the error as confirmation of the finite speed of light; Huygens supported him in his interpretation. Cassini, on the other hand, thought that if this were the case, the same pattern should be apparent in the eclipses of the other three satellites, and it was not (surely because the elements of the orbits of these satellites had not yet been determined as accurately as those for the first satellites). Cassini therefore accounted for the variation by making a geometric correction to the orbit of the first satellite, and then applying this as well to the orbits of the other three. For being on the "wrong" side of the first demonstration of the finite velocity of light, Cassini has been slated, beginning with Edmond Halley in 1694.

Historians have treated Huygens more kindly. After all, his contributions to science spoke for themselves: the pendulum clock, the ring of Saturn, the construction of a wave front which was the foundation of the wave theory of light, his very long telescopes, his contributions to probability theory, and last but not least, his contributions to mathematical physics. Although he was isolated in The Hague at the end of his life, his posthumous Cosmotheoros was a best-seller in all the major European languages. In that book he still maintained that Saturn's ring was a solid structure with a thickness of some thousands of miles, though others (including Cassini!) had long since begun considering it as a swarm of very small satellites - it was in this form that Saturn's ring became a model for evolutionary cosmological speculations of the second half of the eighteenth century.

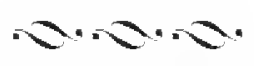




\section{N O T E S}

1 Galileo to Belisario Vinta, 30 July 1610, Le Opere di Galleo Galilei, Edizione Nazionale. 20 vols. ed. Antonio Favaro (Florence:Giunti, 1890-1909; reprints 1929-1939, 1964-1966), X: 410.

2 Galileo's third sunspot letter, I6I3. Ibid., v: 237.

3 Galieo to Federico Cesi, cited in Giovanni Faber to Frederico Borromeo, 3 September I6I6. Ibid., xiI: 276.

4 Christopher Wren, "De Corpore Saturni" (1658). See Albert van Helden, "Christopher Wren's De Corpore Saturni, "Notes and Records of the Royal Society of Lotidon, 23 (1968): 213-229, at 219.

5 Ovid, Fasti. Book I, line 305. "They brought the distant stars closer to our eyes." Huygens sent this anagram to a few correspondents in March I655, and in 1656 sent them the solution: "Saturno luna sua cicunducittr diebus sexdecim horis quatuor," or "Its moon goes around Saturn in sixteen days and four hours."

6 Christiaan Huygens, De Saturni Luna Observation Nova (The Hague, I656), Oeuvres Complètes 15: 177

7 Van Helden, "Christopher Wren's De Corpore Saturni," (note 4), 284, 285.

8 Christopher Wren to Sir Paul Neile, I October I66r (Julian). See C. A. Ronan and Sir Harold Hartley, "Sir Paul Neile, F.R.S.," Notes and Records of the Royal Society of London 15 (1960): $159-65$, at p. 163.

9 Christiaan Huygens, Systema Saturnium (I650), Oenvres Complètes, XV: p. 299.

10 The modern figures are 93 million miles and $8.8^{\prime \prime}$.

11 Oeuvres Complètes, $\mathrm{xV}$ : $27 \mathrm{I}$.

12 Hevelius to Boulliau, 9 December 1659, Paris, Bibliothèque Nationale, MSS "Collection Boulliau" xxv (FF I3042), ff. $87^{\mathrm{r}}-92^{\mathrm{v}}$, at f. $88^{\mathrm{v}}$.

13 Ibid.

14 Systema Saturnium, Oeuvres Complètes, xv; p. 279.

15 Brevis Annotatio. Sec Oetures Complètes, xv: p. 406. 
16 lbid, 423.

17 Michelangiolo Ricci to Prince Leopold, 26 July I660, Florence, Biblioteca Nazionale Centrale, MSS Gal. 276, ff. $42^{\mathrm{r}}-42^{\mathrm{v}}$.

18 This included a reprint of Brevis Annotatio. The full title is Christiani Hugenii Zulichemii Brevis

19 For a full-length biographical study of Cassini, see Anna Cassini, Gio: Domenico Cassini: uno scienzato del Seicento (Perinaldo: Comune di Perinaldo, 1994; second ed., 2003.

20 Tabulae Quotidianae Revolutions macularum Iovis. Nuperrime adinventae a loanne Dominico Cassino (Bologna, I665); Martis revolutio circa axem proprium a I. D. Cassino Telescopio I. Campani observata... (Bologna I666); Ephemerides Bononienses Mediceorum Syderum (Bologna, 1668).

21 Anna Cassini, Gio: Domenico Cassini (note 19), pp. 210-211.

22 John Olmsted, "The Scientific Expedition of Jean Richer to Cayenne," Isis, 34 (1942): 117-128. See also Van Helden, Measuring the Universe: Cosmic Dimensions from Aristarchus to Halley (Chicago: University of Chicago Press, 1985), pp. I29-143.

23 Van Helden,"Longitude and the Satellites of Jupiter," in The Quest for Longitude, ed. William J. H. Andrewes (Cambridge: Harvard University Press, I996), pp. 86-100, at 93-97. 


\section{O L O P H O N}

The text of Huygens's Ring, Cassini's Division and Saturn's Children was composed in Dante, a typeface designed after World War II and completed in 1957 by Giovanni Mardersteig (1892-1977), closely working with punchcutter Charles Malin (1883-1955). Mardersteig, a printer, book designer and typeface artist, was renown for the work produced from his two printing offices in Italy. He had a passion for designing typefaces, and in conjunction with Malin, the two worked together to produce most all of his tyepface designs, starting with Mardersteig's earlier fonts based on the work of Giambattista Bodoni (1740-1813). Dante was the last collaboration for this unique team and it embodies much of what Mardersteig learned to make a font not only readable, but also dynamic and good-looking. The typeface initially appeared in Boccaccio's Trattatello in Laude di Dante in 1955, from which it derives its name. Originally produced for hot metal composition, the digital version that appears in this publication was redrawn from the original characters by Ron Carpenter (b. 1950) and published by Monotype in 1993 . 


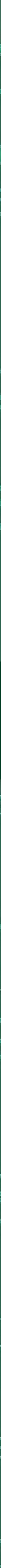

